\title{
Photoreceptor Cell
}

National Cancer Institute

\section{Source}

National Cancer Institute. Photoreceptor Cell. NCI Thesaurus. Code C12634.

A sensory neuron, located in the retina of the eye, that converts light signals into nerve impulses. 